\title{
Ghrelin inhibits ovarian epithelial carcinoma cell proliferation in vitro
}

\author{
YANG XU, XIAOYAN PANG, MEI DONG, FANG WEN and YI ZHANG \\ Department of Gynecology, the First Affiliated Hospital of China Medical University, \\ Shenyang, Liaoning 110001, P.R. China
}

Received April 24, 2013; Accepted June 18, 2013

DOI: $10.3892 /$ or.2013.2692

\begin{abstract}
The only orexigenic peptide, ghrelin, which is primarily produced by the gastrointestinal tract, has been implicated in malignant cell proliferation and invasion. Ghrelin is a natural ligand of the growth hormone secretagogue receptor 1a (GHSR1a). However, the role of ghrelin in ovarian epithelial carcinoma remains unknown since the expression of GHSR1a in ovary is not confirmed. The aim of the present study was to assess expression of ghrelin and its receptor in human ovarian epithelial carcinoma and to examine the effect of ghrelin on carcinoma cell proliferation. Frozen sections of ovarian samples and the human ovarian epithelial carcinoma cell line, HO-8910, were used to characterize the expression of ghrelin/GHSR1a axis and the effect of ghrelin on proliferation. We found that ghrelin and GHSR1a are expressed in ovarian epithelial carcinoma in vivo and in vitro. Ghrelin inhibits the proliferation and growth of HO- 8910 cells by G1 phase arrest, and this inhibition may be abolished by the ghrelin receptor antagonist D-Lys-3GH-releasing peptide- 6 and ghrelin neutralizing antibody. Ghrelin enhances HO-8910 cell apoptosis and autophagy. The activation of mammalian target of rapamycin (mTOR) signaling pathway blocks the effects of ghrelin-induced autophagy and apoptosis, therefore reverses the inhibition of HO-8910 cell proliferation induced by ghrelin. In conclusion, the present study demonstrates that ghrelin inhibits the proliferation of human HO-8910 ovarian epithelial carcinoma cells by inducing apoptosis and autophagy via the mTOR signaling pathway. This study provides a novel regulatory signaling pathway of ghrelin-regulated ovarian epithelial carcinoma growth and may contribute to ovarian cancer prevention and therapy.
\end{abstract}

Correspondence to: Dr Yi Zhang, Department of Gynecology, the First Affiliated Hospital of China Medical University, 155 Nanjing North Street, Shenyang, Liaoning 110001, P.R. China

E-mail: syzi960@yahoo.com

Key words: ghrelin, proliferation, apoptosis, autophagy, mammalian target of rapamycin, ovarian epithelial carcinoma

\section{Introduction}

Ovarian cancer is one of the most common causes of mortality among all cancers in females and is the leading cause of mortality from gynecological malignancies. Ovarian epithelial carcinoma is a common malignant ovarian neoplasm with a poor 5-year survival rate $(<30 \%)$. Many factors regulate the rapid growth of ovarian epithelial carcinoma. The autocrine secretion hypothesis proposes that as a result of oncogene activation, neoplastic cells can escape growth-restraining mechanism by independently producing and responding to their own growth factors $(1,2)$. One relatively newer but exciting dimension is the role of ghrelin in malignant cell proliferation (3).

Ghrelin, a 28 -amino acid peptide hormone, is primarily produced and secreted by the gastrointestinal tract (4). Since its discovery, it has been implicated in a wide range of physiological activities (5). Ghrelin is the only currently identified circulating orexigenic hormone that is able to initiate food intake. A variety of other and pathophysiological processes are known to be regulated by ghrelin in addition to ingestive behavior, including roles in the regulation of growth hormone release, metabolism, the cardiovascular system and insulin secretion (5). Ghrelin is the ligand for the growth hormone secretagogue receptor (GHSR). These receptors have two known subtypes, GHSR1a and GHSR1b $(5,6)$. GHSR1a is reserved for ghrelin's endocrine activities, including the stimulation of appetite and growth hormone secretion, while the latter is thought to be devoid of any mechanistic role.

Ghrelin and its receptor are expressed in a number of cancers and cancer cell lines such as pituitary adenomas, thyroid follicular cancer, parathyroid adenomas, pancreatic-related endocrine tumors, oral squamous cell carcinoma, gastric carcinoids, colon cancer, renal carcinoma, bronchial carcinoid, testicular and ovarian tumors, adrenocortical tumors, prostate cancer and breast cancer, and may play a role in processes associated with cancer progression, including cell proliferation, apoptosis and cell invasion and migration (7). However, the reports are controversial. To date, several groups have reproduced ghrelin's pro-proliferative effect in neuronal, adrenal, prostatic, adipose, mammary, chondroblastic and pancreatic cells (8-11). In contrast to the above mentioned reports, the antiproliferative role of ghrelin has been determined in a few cell types, for example, human CALU-1 lung carcinoma cells (12). 
In the present study, we demonstrated that the proliferation of human ovarian epithelial carcinoma cells was inhibited by ghrelin and explored the mediating mechanism and possible significance.

\section{Materials and methods}

Chemicals and reagents. HO-8910, a human ovarian epithelial carcinoma cell line, was purchased from the American Type Culture Collection (ATCC, Manassas, VA, USA). RPMI-1640 medium was purchased from Hyclone Co. (Logan, UT, USA). Recombinant human ghrelin, an anti-ghrelin neutralizing antibody and the GHSR1a antagonist D-Lys-3-GH-releasing peptide-6 (D-Lys-3-GHRP-6) were purchased from Phoenix Pharmaceuticals (Belmont, CA, USA). Goat anti-human GHSR1a, mouse anti- $\beta$-actin antibodies and purified goat IgG were purchased from Santa Cruz Biotechnology, Inc. (Santa Cruz, CA, USA). All other antibodies were purchased from Cell Signaling Technology (Beverly, MA, USA). All other chemicals and drugs were purchased from Sigma Chemical (St. Louis, MO, USA).

Immunohistochemical analysis. Frozen sections of ovarian samples were incubated with the goat primary anti-human GHSR1a antibody or purified goat $\mathrm{IgG}$, horseradish peroxidase-conjugated mouse anti-goat IgG and 3,3-diaminobenzidine successively. Sections were then counterstained with hematoxylin.

Cell culture. HO-8910 cells were cultured in RPMI-1640 containing $10 \%$ fetal bovine serum (FBS) and penicillin/ streptomycin $(100 \mathrm{U} / \mathrm{ml})$ in a humidified $37^{\circ} \mathrm{C}$ incubator. When achieving confluence, the cells were treated with ghrelin $\left(10^{-11}\right.$ $10^{-8} \mathrm{M}$ ) for $48 \mathrm{~h}$. For the inhibition experiments, cells were pretreated with L-leucine or 3-methyladenine (3-MA) for $1 \mathrm{~h}$ prior to stimulation with ghrelin at $10^{-9} \mathrm{M}$ for $48 \mathrm{~h}$.

RNA extraction and RT-PCR analysis. Total RNAs were isolated using Trizol reagent according to the manufacturer's instructions. Total RNA ( $2 \mu \mathrm{g}$ ) was reverse-transcribed using reverse transcription system (Promega, Madison, WI, USA). One microliter of the reaction mixture was subjected to PCR. The forward and reverse PCR primers were: human ghrelin, 5'-TGA GCC CTG AAC ACC AGA GAG-3' and 5'-AAA GCC AGA TGA GCG CTT CTA-3' (Genebank sequence ID: NM_016362.3); human GHSR1a, 5'-TCG TGG GTG CCT CGC T-3' and 5'-CAC CAC TAC AGC CAG CAT TTT C-3' (Genebank sequence ID: NM_198407.2); human proliferating cell nuclear antigen (PCNA), 5'-TGT TGG AGG CAC TCA AGG AC-3' and 5'-TCA TTG CCG GCG CAT TTT AG-3' (Genebank sequence ID: NM_002592.2); human $\beta$-actin, 5'-ATC TGG CAC CAC ACC TTC-3' and 5'-AGC CAG GTC CAG ACG CA-3' (Genebank sequence ID: NM_001101.3). All amplification reactions were performed under the following conditions: $95^{\circ} \mathrm{C}$ for $5 \mathrm{~min}$, followed by 35 cycles at $95^{\circ} \mathrm{C}$ for $30 \mathrm{sec}, 58^{\circ} \mathrm{C}$ for $30 \mathrm{sec}$ and $72^{\circ} \mathrm{C}$ for $60 \mathrm{sec}$. A $20 \mu \mathrm{l}$ aliquot of the RT-PCR samples was loaded onto $1.5 \%$ agarose gel. For the quantitative real-time PCR analysis, the amount of PCR products formed in each cycle was evaluated on the basis of SYBR-Green I fluorescence. Results were analyzed with
Stratagene Mx3000 software, and mRNA levels were normalized with respect to the levels of $\beta$-actin in each sample. For negative controls, PCR reactions were performed for the primer pairs in the absence of the transcript.

Cell proliferation and viability assays. To determine the effect of ghrelin on HO-8910 cell proliferation, 30\% confluent HO-8910 cells were incubated in RPMI-1640 media with different concentrations of FBS $(0,5$ and $10 \%)$ in the presence or absence of ghrelin $\left(10^{-9} \mathrm{M}\right)$ for $48 \mathrm{~h}$. On completion of the incubation, cultures were typsinized and cell numbers were determined with an Invitrogen CountessH Automated Cell Counter (Invitrogen, Carlsbad, CA, USA).

The WST-1 and Cell Counting Kit-8 (CCK-8) assays were used to determine the effect of ghrelin on HO-8910 cell viability. Briefly, $1 \times 10^{3}$ cells/well were incubated in 96-well plates overnight, starved in serum-free medium for $24 \mathrm{~h}$ and treated with indicated reagents. For the WST-1 assay (BioVision Research Products, Milpitas, CA, USA), cells were incubated with $10 \mu \mathrm{l}$ of WST-1 reagent for $45 \mathrm{~min}$ and the absorbance was measured at $450 \mathrm{~nm}$ using the Bio-Rad iMark microplate absorbance reader (Bio-Rad, USA). For the CCK-8 assay (Dojindo Molecular Technologies, Inc., Kumamoto, Japan), cells were incubated with $10 \mu \mathrm{l}$ of CCK-8 solution for $1 \mathrm{~h}$ and the absorbance was measured at $450 \mathrm{~nm}$.

Cell cycle analysis. HO-8910 cells, cultured with or without ghrelin $\left(10^{-9} \mathrm{M}\right)$ for $24 \mathrm{~h}$, were trypsinized, fixed and permeabilized with $70 \%$ ethanol. Cells were then labeled with propidium iodide with RNase A cocktail for $30 \mathrm{~min}$ at $37^{\circ} \mathrm{C}$, and flow cytometry was used to determine the cell cycle distribution of the HO-8910 cells. Data were obtained using the FACSCalibur flow cytometer (BD Biosciences, USA).

Apoptosis analysis. HO-8910 cells were cultured in a 96-well plate with or without ghrelin $\left(10^{-9} \mathrm{M}\right)$ stimulation. Apoptosis was assessed by measuring cysteine aspartic acid-specific protease (caspase) 3/7 activity with the use of the Caspase-Glo ${ }^{\circledR} 3 / 7$ assay kit (Promega) according to the manufacturer's instructions.

Preparation of cytosolic proteins and western blot analysis. Following treatment, the cells were packed by centrifuging the cells for $3 \mathrm{~min}$ at $200 \mathrm{x} \mathrm{g}$, and homogenized in ice-cold fractionation buffer [50 mM Tris- $\mathrm{HCl}, \mathrm{pH} 7.4,1 \mathrm{mM}$ EDTA, $150 \mathrm{mM} \mathrm{NaCl}, 1 \%$ Triton X-100, 1 mM PMSF, $10 \mu \mathrm{g} / \mathrm{ml}$ leupeptin, $10 \mu \mathrm{g} / \mathrm{ml}$ pepstatin $\mathrm{A}, 10 \mu \mathrm{g} / \mathrm{ml}$ aprotinin, $1 \mathrm{mM}$ sodium orthovanadate $\left(\mathrm{Na}_{3} \mathrm{VO}_{4}\right), 10 \mathrm{mM}$ sodium pyrophosphate $\left(\mathrm{Na}_{4} \mathrm{P}_{2} \mathrm{O}_{7}\right)$ and $50 \mathrm{mM}$ sodium fluoride $\left.(\mathrm{NaF})\right]$. The cell lysate was incubated on ice for $15 \mathrm{~min}$ and then centrifuged at $20,000 \mathrm{x} \mathrm{g}$ for $30 \mathrm{~min}$ at $4^{\circ} \mathrm{C}$. The cytosolic fraction was collected and subjected to SDS-PAGE with a $10 \%$ running gel. Protein concentrations were determined by BCA protein assay kit (Pierce, Rockford, IL, USA). The proteins were transferred to a polyvinylidene fluoride membrane. The membrane was incubated successively with $5 \%$ bovine serum albumin in TrisTween buffered saline (TTBS) at room temperature for $1 \mathrm{~h}$, with different primary antibodies at $4^{\circ} \mathrm{C}$ for $12 \mathrm{~h}$ and then with horseradish peroxidase-labeled secondary antibody for $1 \mathrm{~h}$. After each incubation, the membrane was washed extensively 
A

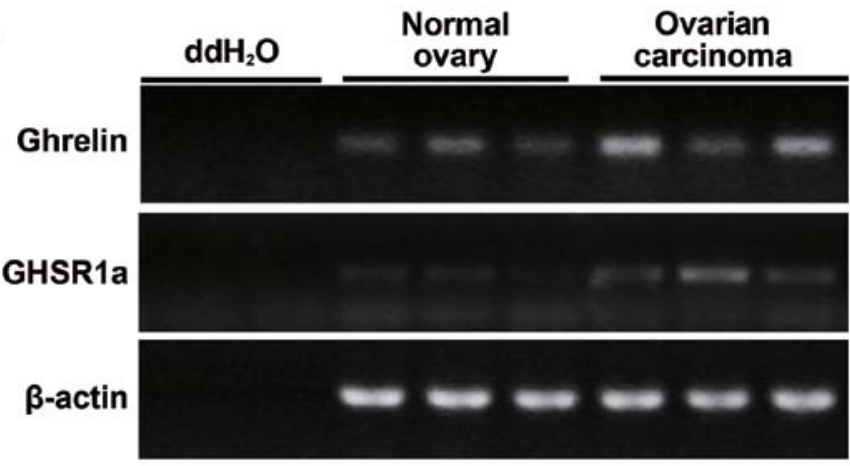

B

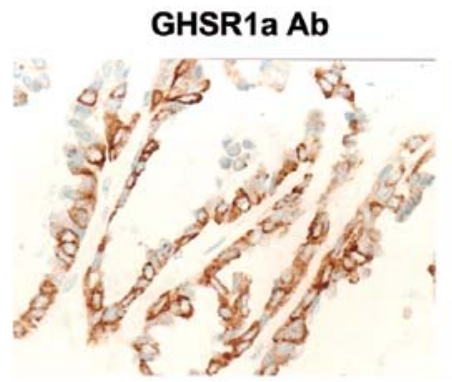

$\lg \mathbf{G}$

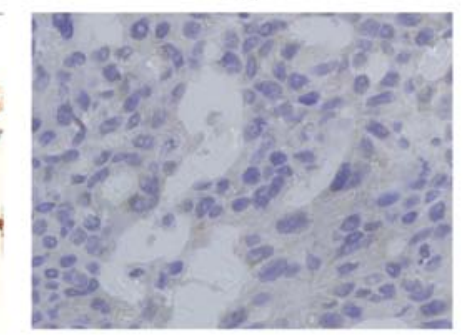

C

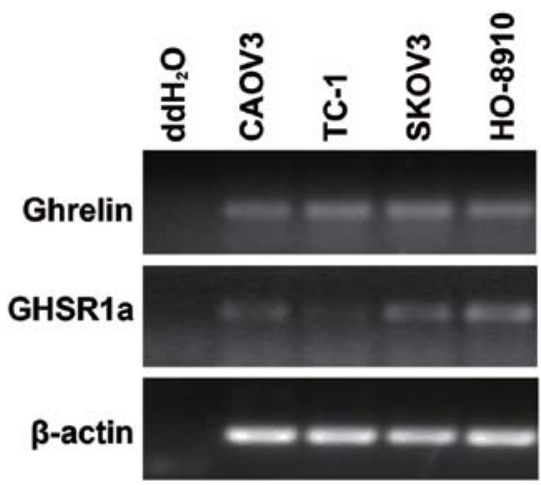

Figure 1. Ghrelin and growth hormone secretagogue receptor 1a (GHSR1a) are expressed in ovarian epithelial carcinoma in vivo and in vitro. (A) Ghrelin and GHSR1a mRNA expression in normal ovarian and ovarian epithelial carcinoma tissues. (B) Immunohistochemical analysis of sections from ovarian epithelial carcinoma samples with a specific anti-GHSR1a antibody. Purified IgG was used as the control. Magnification, x400. (C) Ghrelin and GHSR1a mRNA expression in ovarian epithelial carcinoma cell lines. For negative controls, PCR reactions were performed for the primer pairs in the absence of the transcript.

with TTBS and the immunoreactive band was detected with ECL detecting reagents (Pierce).

Statistical analysis. Quantitative data are presented as the means \pm SEM determined from the indicated number of experiments. Statistical analysis was based on the Student's t-test for comparison of two groups or one-way ANOVA for multiple comparisons. $\mathrm{P}<0.05$ was used to determine statistical significance.

\section{Results}

Ghrelin and GHSRla are expressed in ovarian epithelial carcinoma in vivo and in vitro. We first examined whether ghrelin and GHSR1a, the classical ghrelin receptor, are expressed in ovarian epithelial carcinoma tissues in vivo. RT-PCR analysis showed that ghrelin was expressed in normal ovarian tissues as well as in ovarian epithelial carcinoma tissues (Fig. 1A), with a higher level of ghrelin in ovarian epithelial carcinoma. GHSR1a was expressed in ovarian epithelial carcinoma tissues, but was barely expressed in normal ovarian tissues (Fig. 1A). Immunohistochemical staining also showed that GHSR1a was expressed in ovarian epithelial carcinoma tissues (Fig. 1B). Ghrelin was expressed in all the human ovarian carcinoma cell lines tested, but the highest expression of GHSR1a was detected in the HO- 8910 cells (Fig. 1C). These results confirmed the existence of ghrelin and GHSR1a in ovarian epithelial carcinoma and were consistent with a previous report (13).

Ghrelin inhibits HO-8910 cell proliferation. We next study the possible role of ghrelin in ovarian epithelial carcinoma progression. HO-8910, a human ovarian epithelial carcinoma cell line, was cultured without (control) or with ghrelin $\left(10^{-9} \mathrm{M}\right)$ for $48 \mathrm{~h}$ 

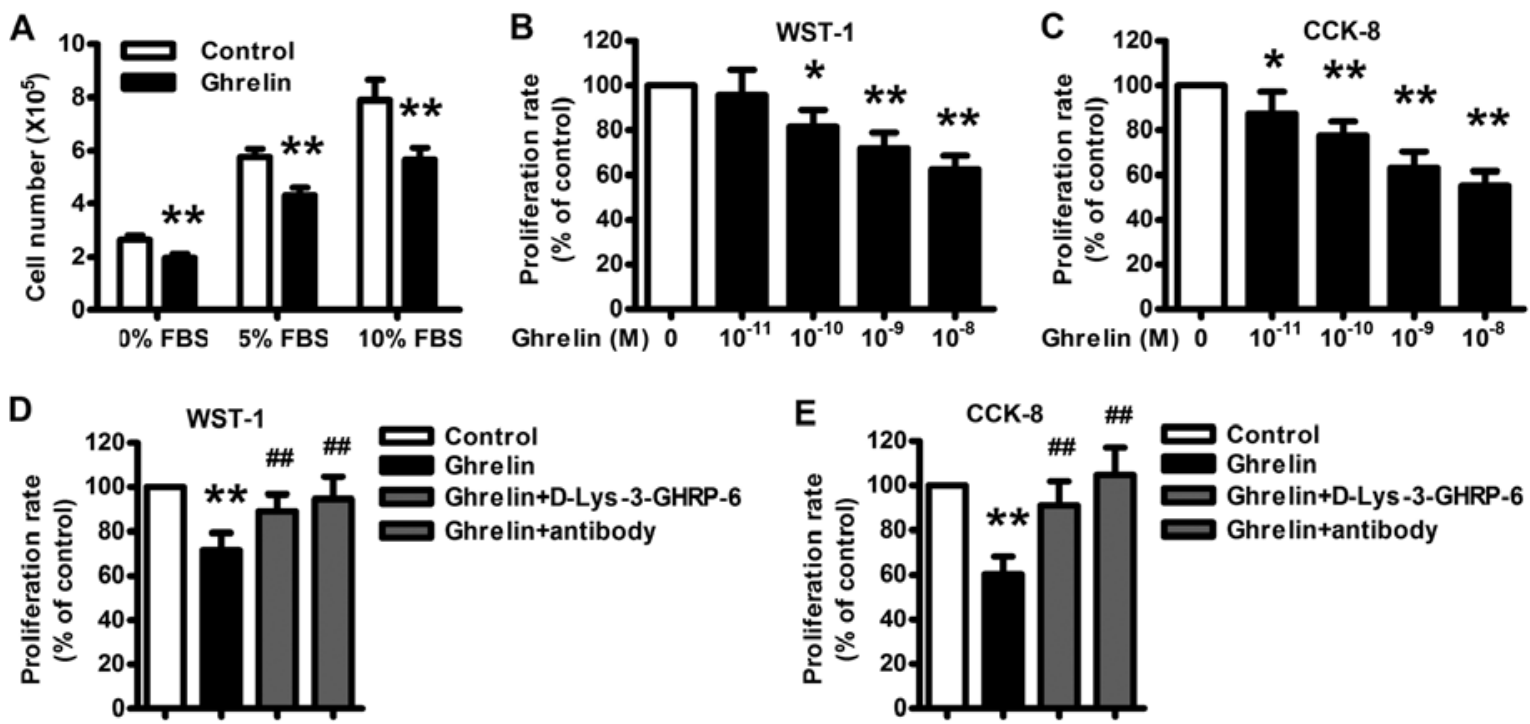

Figure 2. Effect of ghrelin on HO-8910 cell proliferation. (A) HO-8910 cells were treated without (control) or with ghrelin (10 $\left.0^{-9} \mathrm{M}\right)$ supplied with increasing amounts of serum for $48 \mathrm{~h}$, and cell numbers were assessed. (B and C) HO-8910 cells were treated with the indicated dosages of ghrelin for $48 \mathrm{~h}$, and cell viability was detected using the WST-1 and CCK-8 assays. (D and E) Augmentation of ghrelin-inhibited proliferation by the anti-ghrelin neutralizing antibody or the GHSR1a antagonist. Cells were pretreated with or without the neutralizing antibody (1:1,000) or D-Lys-3-GH-releasing peptide-6 (D-Lys-3-GHRP-6; $1 \mathrm{mM})$ for $1 \mathrm{~h}$, then incubated in the presence of ghrelin $\left(10^{-9} \mathrm{M}\right)$ for $48 \mathrm{~h}$. Data are means \pm SEM from 4 separate experiments. ${ }^{*} \mathrm{P}<0.05,{ }^{* * *} \mathrm{P}<0.01 \mathrm{vs}$. ghrelin-untreated cells; ${ }^{\# \#} \mathrm{P}<0.01$ vs. ghrelin treatment alone.
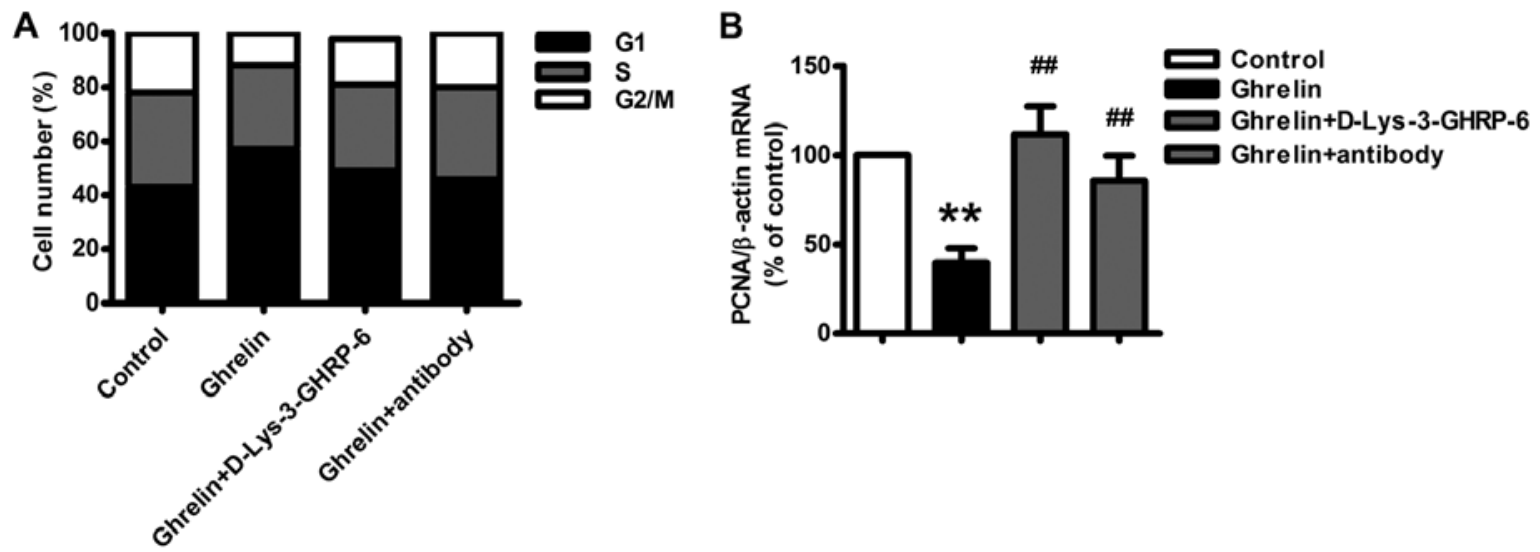

Figure 3. Effect of ghrelin on HO-8910 cell cycle progression. (A) HO-8910 cells were treated without (control) or with ghrelin (10-9 $\mathrm{M})$ and/or the anti-ghrelin neutralizing antibody or the GHSR1a antagonist for $24 \mathrm{~h}$, and cell cycle progression was determined by flow cytometry. (B) Expression of proliferating cell nuclear antigen (PCNA) in HO-8910 cells following treatment with ghrelin, the anti-ghrelin neutralizing antibody or the GHSR1a antagonist. Relative mRNA levels were normalized to that of the untreated cells. The results are representative of 4 independent experiments. Data are means $\pm S E M$. ${ }^{* *} \mathrm{P}<0.01 \mathrm{vs}$. untreated cells; ${ }^{\# \#} \mathrm{P}<0.01$ vs. ghrelin treatment alone.

with different concentrations of FBS. Treatment of HO-8910 cells with ghrelin resulted in a statistically significant decrease in cell number compared to the control (Fig. 2A). Treatment with increasing amounts of serum resulted in a concentrationdependent increase in cell number. The inhibitory effect of ghrelin was still significant with increasing concentrations of serum in the cell culture medium.

The WST- 1 and CCK- 8 assays also revealed that ghrelin treatment $\left(10^{-11}-10^{-8} \mathrm{M}\right)$ for $48 \mathrm{~h}$ resulted in a concentration-dependent inhibition in HO-8910 cell proliferation (Fig. 2B and C), with maximal inhibition of $~ 62$ and $54 \%$ of the control noted at $10^{-8} \mathrm{M}$ of ghrelin. A neutralizing antibody of ghrelin significantly attenuated the HO-8910 cell proliferation (Fig. 2D and E), similarly as the GHSR1a antagonist D-Lys-3-
GHRP-6, which indicates that ghrelin-mediated inhibition of HO-8910 cell proliferation depends on the immune activity of ghrelin and through its receptor.

Alteration of the cell cycle distribution of HO-8910 cells following ghrelin treatment. Flow cytometry was used to evaluate the effect of ghrelin on HO-8910 cell cycle progression. Ghrelin $\left(10^{-9} \mathrm{M}\right)$ significantly increased the proportion of cells in the G1 phase by $\sim 38.1 \%$ ( $\mathrm{P}<0.01$ ) (Fig. 3A), and the proportion of $\mathrm{G} 2 / \mathrm{M}$ and $\mathrm{S}$ phase cells was decreased by a comparable degree, which indicated that ghrelin effectively inhibited the proliferation and growth of HO-8910 cells by G1 phase arrest. The expression of PCNA, a novel proliferationrelated gene usually highly expressed in the G1/S phase, was 
A

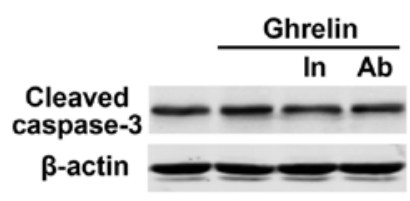

B

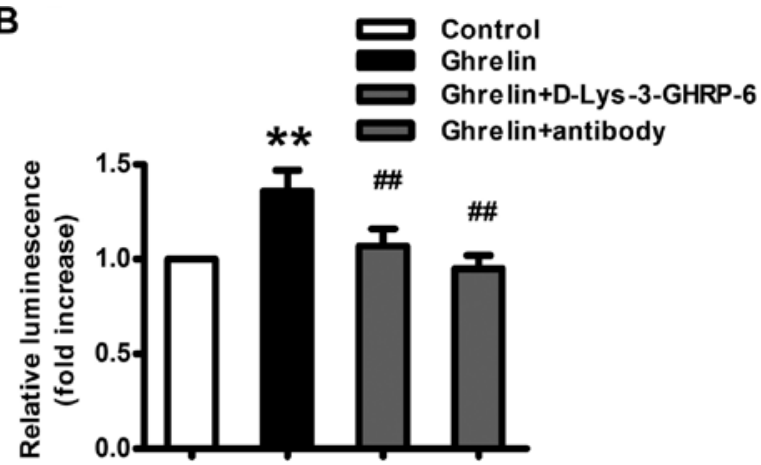

Figure 4. Ghrelin promotes apoptosis in HO-8910 cells. (A) Western blot analysis of ghrelin-induced cleaved caspase-3 protein levels in HO-8910 cells. (B) Caspase-3 and -7 activity detected in HO-8910 cells following treatment with ghrelin. Cells were pretreated with the anti-ghrelin neutralizing antibody or the growth hormone secretagogue receptor 1a (GHSR1a) antagonist for $1 \mathrm{~h}$ and then with ghrelin $\left(10^{-9} \mathrm{M}\right)$ for $48 \mathrm{~h}$. Data are means \pm SEM from 4 separate experiments. ${ }^{* *} \mathrm{P}<0.01$ vs. ghrelin-untreated cells; ${ }^{* \#} \mathrm{P}<0.01$ vs. ghrelin treatment alone.

A

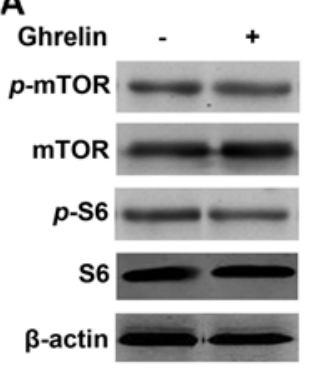

B

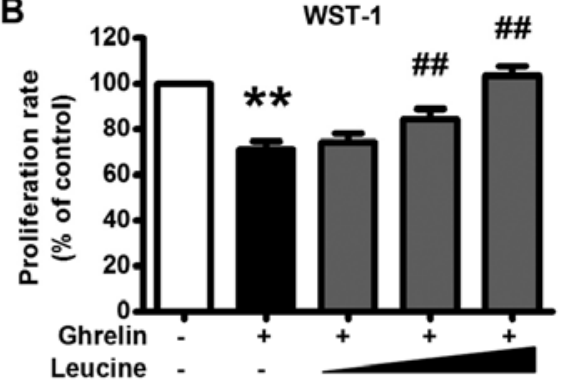

C

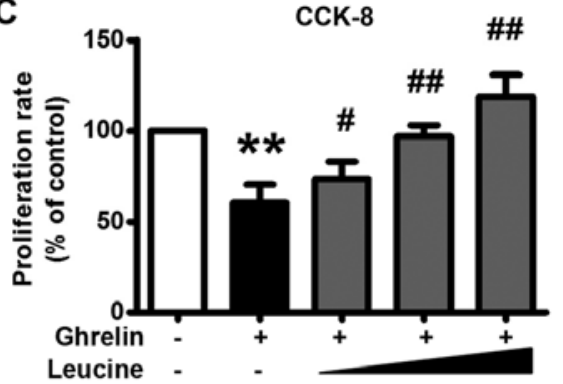

D

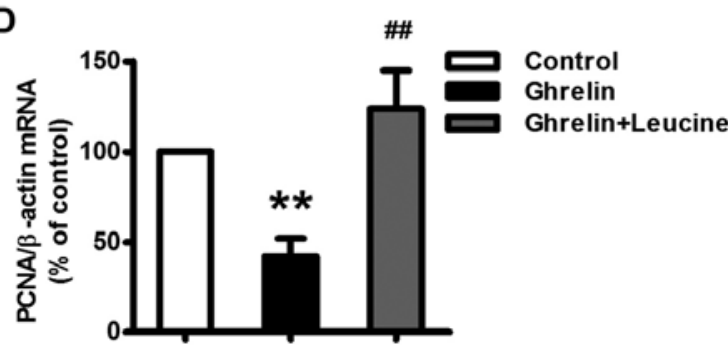

E

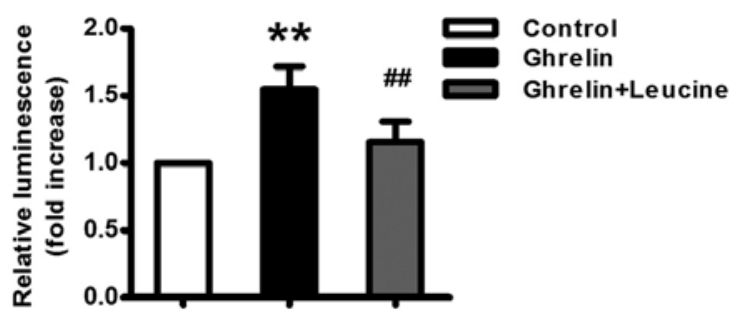

Figure 5. Mammalian target of rapamycin (mTOR) signaling pathway is inhibited upon ghrelin stimulation. (A) Effects of ghrelin on mTOR pathway activation in HO-8910 cells. Cells were incubated with ghrelin $\left(10^{-9} \mathrm{M}\right)$ for $6 \mathrm{~h}$, and whole-cell lysates underwent western blotting to detect the phosphorylation of mTOR (Ser2448) and S6. (B and C) Augmentation of ghrelin-inhibited proliferation by L-leucine (1, 5, $10 \mathrm{mM}$ ) as determined by WST-1 and CCK-8 assays . (D) Attenuation of ghrelin-inhibited proliferating cell nuclear antigen (PCNA) expression by L-leucine in HO-8910 cells. (E) Blockage of ghrelin-induced caspase- 3 and -7 activity by L-leucine in HO- 8910 cells. Cells were pretreated with or without L-leucine $(5 \mathrm{mM})$ for $1 \mathrm{~h}$ and then incubated in the presence of ghrelin $\left(10^{-9} \mathrm{M}\right)$ for $48 \mathrm{~h}$. Data are means \pm SEM from 4 separate experiments. ${ }^{* *} \mathrm{P}<0.01$ vs. ghrelin-untreated cells; ${ }^{\#} \mathrm{P}<0.05$, ${ }^{\# \#} \mathrm{P}<0.01$ vs. ghrelin treatment alone.

also significantly inhibited by ghrelin (Fig. 3B). A neutralizing antibody of ghrelin and the GHSR1a antagonist D-Lys-3GHRP-6 also significantly attenuated the effect of ghrelin on the cell cycle (Fig. 3).

Ghrelin promotes apoptosis in $\mathrm{HO}-8910$ cells. The members of the caspase family play key effector roles in apoptosis in mammalian cells. We next detected the effect of ghrelin on the apoptosis of HO-8910 cells. As expected, ghrelin $\left(10^{-9} \mathrm{M}\right)$ significantly increased the production of the apoptosis marker, cleaved caspase-3 (Fig. 4A). The activity of caspase-3 and -7 was also significantly increased following ghrelin treatment (Fig. 4B). These effects were dependent on the immune activity of ghrelin and through its receptor since both the neutralizing antibody of ghrelin and the GHSRla antagonist significantly attenuated the effect of ghrelin on HO-8910 cell apoptosis (Fig. 4).
Mammalian target of rapamycin (mTOR) signaling pathway is inhibited upon ghrelin stimulation. The mTOR is a central cell-growth regulator that regulates cell proliferation, and aberrant mTOR activity is linked to the development of cancer (14). In the present study, we found that there was a significant decrease in phosphorylated mTOR (Ser2448) following ghrelin treatment $\left(10^{-9} \mathrm{M}\right)$, as well as the phosphorylation of S6 ribosomal protein, a downstream target of mTOR (Fig. 5A). Administration of L-leucine (1, 5, $10 \mathrm{mM}$ ), a branched-chain amino acid that has been documented to activate mTOR signaling (15), significantly restored ghrelin-inhibited HO-8910 cell proliferation (Fig. 5B-D). Administration of L-leucine $(5 \mathrm{mM})$ also significantly attenuated ghrelin-induced HO-8910 cell apoptosis (Fig. 5E). Taken together, ghrelin inhibited HO-8910 cell proliferation through inhibition of the mTOR signaling pathway. 
A

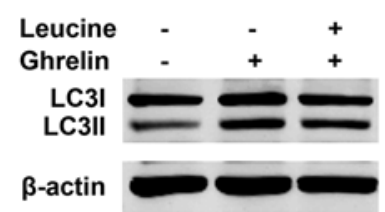

B

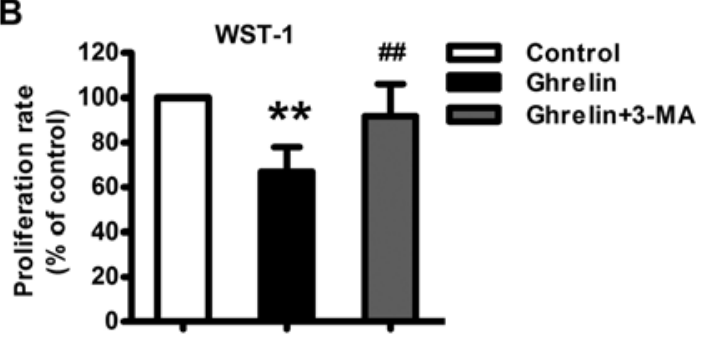

C
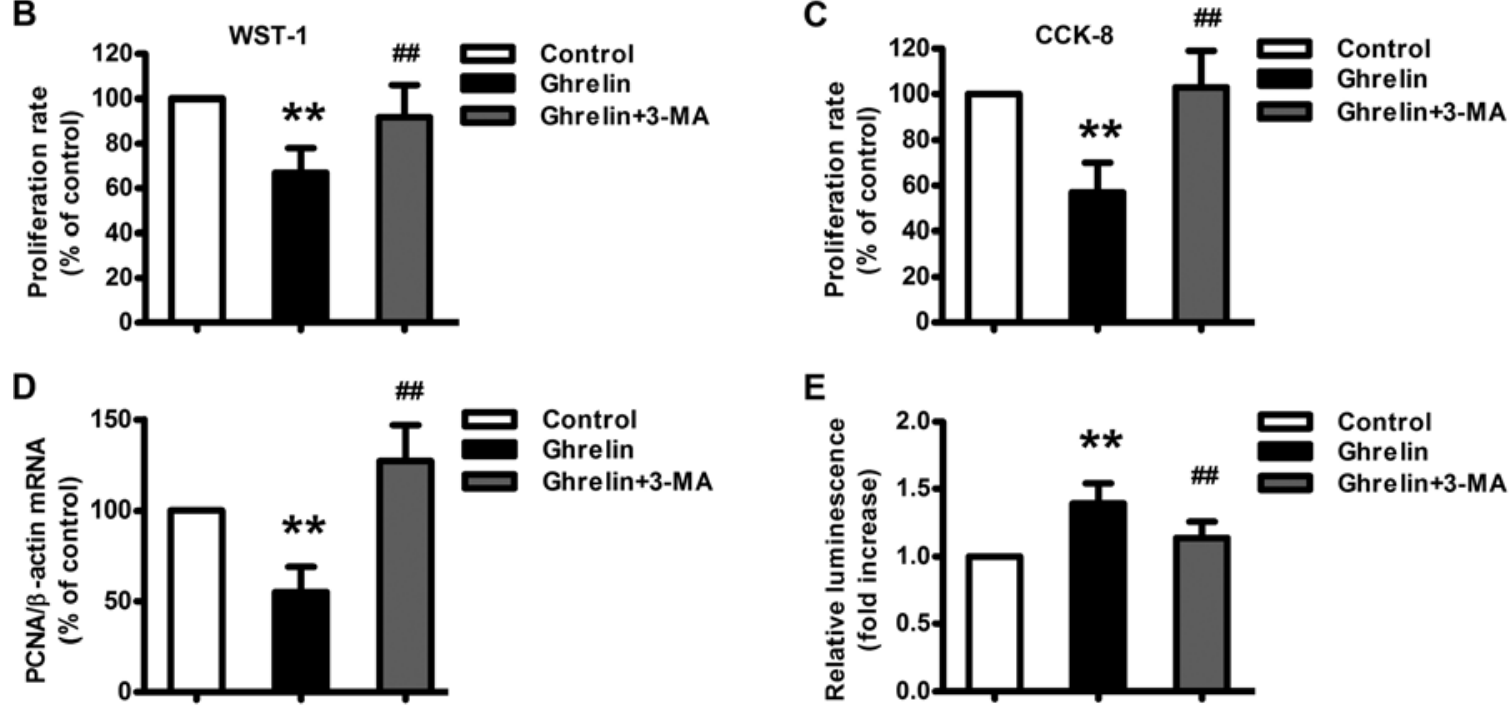

E

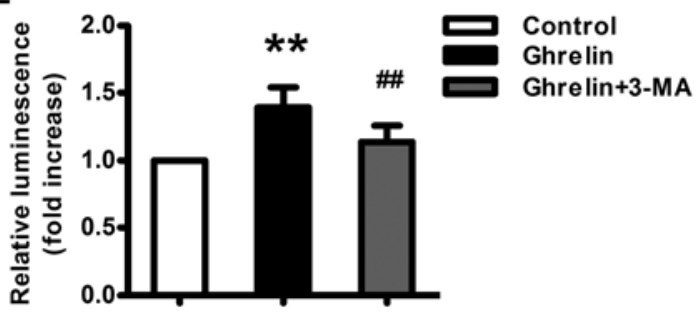

Figure 6. Ghrelin induces autophagy in HO-8910 cells. (A) Western blot analysis of light-chain 3-II (LC3II) levels in HO-8910 cells treated with ghrelin $\left(10^{-9} \mathrm{M}\right)$ and/or L-leucine (5 mM) for $12 \mathrm{~h}$. (B-D) Augmentation of ghrelin-inhibited proliferation by the autophagy inhibitor, 3-methyladenine (3-MA) (E) Attenuation of ghrelin-induced caspase-3 and -7 activity detected in HO-8910 cells treated with the autophagy inhibitor. Cells were pretreated with the autophagy inhibitor $(3-\mathrm{MA} ; 5 \mathrm{mM})$ for $1 \mathrm{~h}$, and then with ghrelin $\left(10^{-9} \mathrm{M}\right)$ for $48 \mathrm{~h}$. Data are means \pm SEM from 4 separate experiments. ${ }^{* *} \mathrm{P}<0.01 \mathrm{vs}$. ghrelin-untreated cells; ${ }^{\# \prime} \mathrm{P}<0.01$ vs. ghrelin treatment alone.

Involvement of autophagy following ghrelin stimulation. Autophagy is a tightly regulated process, and defects in autophagy have been closely associated with many human diseases, including cancer $(16,17)$. To determine whether autophagy is involved in ghrelin-induced apoptosis, we first examined the effect of ghrelin on autophagosome formation in HO-8910 cells. Ghrelin $\left(10^{-9} \mathrm{M}\right)$ significantly increased the level of the lipid-conjugated form of the autophagosome marker light-chain 3-II (LC3II) in HO-8910 cells (Fig. 6A). To address the potential role of autophagy in ghrelin-induced apoptosis in HO-8910 cells, 3-methyladenine (3-MA), a pharmacological inhibitor of autophagy, was used. Pretreatment of 3-MA ( $5 \mathrm{mM})$ for $1 \mathrm{~h}$ significantly attenuated ghrelin-induced HO-8910 cell apoptosis (Fig. 6E) and augmented ghrelininhibited HO-8910 cell proliferation (Fig. 6B-D). Furthermore, L-leucine treatment significantly attenuated ghrelin-induced autophagy (Fig. 6A). Taken together, autophagy-mediated ghrelin-induced apoptosis, is regulated by the mTOR signaling pathway.

\section{Discussion}

The present study demonstrated that ghrelin inhibited the proliferation of the human ovarian epithelial carcinoma cell line HO-8910 through induction of apoptosis and autophagy via the mTOR signaling pathway and may subsequently contribute to cancer prevention and therapy. This conclusion is supported by the following observations. i) Ghrelin and GHSR1a are expressed in ovarian epithelial carcinoma in vivo and in vitro. ii) Ghrelin inhibits the proliferation and growth of HO-8910 cells by G1 phase arrest. iii) Ghrelin enhances HO-8910 cell apoptosis and autophagy. iv) Activation of the mTOR signaling pathway blocks the effects of ghrelin on autophagy and apoptosis, thereby reversing the inhibition of HO-8910 cell proliferation. To the best of our knowledge, this is the first report demonstrating the involvement of multiple signaling pathways in the ghrelin-mediated modulation of proliferation in ovarian epithelial carcinoma.

Ovarian carcinoma is the fourth most common cause of cancer-related death among women in the United States; although it is the 12th most common cause of cancer-related death among women in China, the mortality rate is more than $70 \%$ within 5 years. Although many studies report the effect of ghrelin on the pathogenesis and progression of malignant tumors, it is seldom reported in ovarian carcinoma. The possible reason may be the distribution of ghrelin and GHSR 1a expression. Ghrelin has been found in the stomach, other parts of the gut, adrenal gland, atrium, breast, buccal mucosa, esophagus, Fallopian tube, fat tissue, gall bladder, human lymphocytes, ileum, kidney, left colon, liver, lung, lymph node, muscle, myocardium, ovary, pancreas, pituitary, placenta, prostate, skin, spleen, testis, thyroid and vein (13). However, it was previously reported that the expression of GHSR1a was predominantly expressed only in the pituitary and at much lower levels in the thyroid gland, pancreas, spleen, myocardium and adrenal gland, and not detectable in the ovary (13).

In the present study, we confirmed the expression of GHSR1a in ovarian epithelial carcinoma tissues, which is consistent with a previous report (18). Therefore, ghrelin inhibits HO-8910 cell proliferation through the interaction 
with its receptor directly. It has been reported that in women with ovarian cancer, blood concentrations of active ghrelin were higher than that in the control group; in contrast, total ghrelin concentrations in blood were similar in the studied groups. This alteration resulted in increased ratios of active to total ghrelin concentration in the peripheral blood of patients with ovarian cancer (19). Generally, the structure of ghrelin is unique in that specific acyl-modification of its third serine occurs. This acylation is necessary for ghrelin to bind to GHSR1a, and to exert biologic activity (5). The carboxylic chain that esterifies the hydroxyl of serine is primarily n-octanoic acid, but other 6-10 carbon chain residues may also modify the structure of ghrelin. The enzyme responsible for the acylation of ghrelin is ghrelin $\mathrm{O}$-acyltransferase (GOAT) $(20,21)$, which is highly expressed in the stomach, adrenal cortex, spleen, lung, pituitary, but is barely expressed in the ovary (22). Therefore, although ghrelin is expressed in ovarian tissues, the effect of active acyl ghrelin on ovarian carcinoma may still occur through an endocrine rather than a paracrine/auotcrine pathway. The effect of des-acyl ghrelin, the main component of plasma total ghrelin but which does not bind to GHSR1a $(23,24)$, on the pathogenesis and progression of ovarian epithelial carcinoma is still unknown and warrants further investigation.

The mTOR, a ubiquitously expressed protein kinase and important regulator of cell growth and proliferation, is implicated in cell processes that lead to uncontrolled growth of cancer cells. L-leucine is a specific activator of mTOR (15), and downstream targets of mTOR include S6 kinases, S6 and eIF-4E binding protein $1(25,26)$. Exactly how mTOR contributes to cancer is still unclear. It is believed that mTOR and its downstream signals affect cell proliferation and tumorigenesis by promoting the translation of specific mRNAs coding for pro-oncogenic proteins that regulate cell survival, cell-cycle progression, angiogenesis, energy metabolism and metastasis (27). Additionally, the increase in ribosome biogenesis linked to mTOR activation probably promotes cell proliferation by providing the machinery required to sustain high levels of cell growth. A number of agents that target the mTOR pathway have shown potent antitumorigenic effects (28). The effect of ghrelin on mTOR activity is controversial; ghrelin was reported to elicit a marked upregulation or downregulation of the hypothalamic mTOR signaling pathway. In the present study, we demonstrated the downregulation of the activities of mTOR and its downstream signal S6 following ghrelin treatment in HO-8910 cells. This downregulation mediated ghrelin-inhibited HO-8910 cell proliferation. Two mTOR complexes are known to exist: mTOR complex 1 (mTORC1) is responsible for nutrient-sensing functions and is composed of mTOR, G protein-subunit-like protein and raptor; mTORC2 phosphorylates Akt protein kinase B and contains mTOR and rictor (26). In the present study, we found that L-leucine significantly attenuated ghrelin-induced HO-8910 cell apoptosis and therefore increased proliferation, indicating that mTORC1 mediated the effect of ghrelin. The role of mTORC2 during the effect of ghrelin remains unclear.

Programmed cell death plays a fundamental role in animal development and tissue homeostasis (29). Abnormal regulation of this process is associated with a wide variety of human diseases, including immunological and developmental disorders and cancer. Apoptosis is the most important form of programmed cell death. In the present study, we demonstrated that ghrelin induced the apoptosis of HO-8910 cells and subsequently inhibited tumor growth. However, although ghrelin inhibited the proliferation of HO-8910 cells, it has been previously reported that apoptosis may also induce a compensative proliferation under a certain environment (30). The balance of ghrelin-regulated proliferation and apoptosis warrants further discussion.

Autophagy is a dynamic and highly regulated process of self-digestion. It is a highly conserved cellular process responsible for removal or recycling of long-lived proteins and organelles, and provides cells with an alternative source of nutrients from the reuse of cellular proteins and organelles $(31,32)$. Induced autophagy can contribute to or enhance the apoptotic response (33), although limited autophagy in response to nutrient starvation can prevent the activation of apoptotic pathways (34). Defects in autophagy have been closely associated with many human diseases, including cancer, myopathy and neurodegeneration. Autophagy has also been implicated in the clearance of pathogens and antigen presentation. In the present study, we found that ghrelin-induced autophagy enhanced apoptosis and inhibited proliferation, which indicates that autophagy is beneficial for controlling tumor growth following ghrelin stimulation. The inhibitory function of mTORC1 in autophagy is well established $(35,36)$. Our finding that activation of mTOR by L-leucine inhibited ghrelin-induced autophagy is consistent with these reports.

In summary, the present study demonstrated that ghrelin inhibited the proliferation of human ovarian epithelial carcinoma HO-8910 cells through the induction of apoptosis and autophagy via the mTOR signaling pathway. The present study provides a novel regulatory signaling pathway of ghrelin-regulated ovarian epithelial carcinoma growth and may contribute to ovarian cancer prevention and therapy.

\section{Acknowledgements}

The present study was supported by the Liaoning Natural Science Foundation (no. 2009225035) and the Shenyang Science and Technology Foundation (no. F11-262-9-14) to Y.Z.

\section{References}

1. Billottet C, Janji B, Thiery JP and Jouanneau J: Rapid tumor development and potent vascularization are independent events in carcinoma producing FGF-1 or FGF-2. Oncogene 21: 8128-8139, 2002.

2. Di Blasio AM, Cremonesi L, Viganó P, et al: Basic fibroblast growth factor and its receptor messenger ribonucleic acids are expressed in human ovarian epithelial neoplasms. Am J Obstet Gynecol 169: 1517-1523, 1993.

3. Chopin L, Walpole C, Seim I, et al: Ghrelin and cancer. Mol Cell Endocrinol 340: 65-69, 2011.

4. Kojima M, Hosoda H, Date Y, Nakazato M, Matsuo H and Kangawa K: Ghrelin is a growth-hormone-releasing acylated peptide from stomach. Nature 402: 656-660, 1999.

5. Kojima $\mathrm{M}$ and Kangawa $\mathrm{K}$ : Ghrelin: structure and function. Physiol Rev 85: 495-522, 2005.

6. Smith RG, Leonard R, Bailey AR, et al: Growth hormone secretagogue receptor family members and ligands. Endocrine 14: 9-14, 2001.

7. Majchrzak K, Szyszko K, Pawlowski KM, Motyl T and Król M: A role of ghrelin in cancerogenesis. Pol J Vet Sci 15: 189-197, 2012 . 
8. Zhang W, Lin TR, Hu Y, et al: Ghrelin stimulates neurogenesis in the dorsal motor nucleus of the vagus. J Physiol 559: 729-737, 2004.

9. Kim SW, Her SJ, Park SJ, et al: Ghrelin stimulates proliferation and differentiation and inhibits apoptosis in osteoblastic MC3T3-E1 cells. Bone 37: 359-369, 2005.

10. De Vriese $C$ and Delporte C: Autocrine proliferative effect of ghrelin on leukemic HL-60 and THP-1 cells. J Endocrinol 192: 199-205, 2007.

11. Waseem T, Javaid-Ur-Rehman, Ahmad F, Azam M and Qureshi MA: Role of ghrelin axis in colorectal cancer: a novel association. Peptides 29: 1369-1376, 2008.

12. Ghè $\mathrm{C}$, Cassoni $\mathrm{P}$, Catapano $\mathrm{F}$, et al: The antiproliferative effect of synthetic peptidyl GH secretagogues in human CALU-1 lung carcinoma cells. Endocrinology 143: 484-491, 2002.

13. Gnanapavan S, Kola B, Bustin SA, et al: The tissue distribution of the mRNA of ghrelin and subtypes of its receptor, GHS-R, in humans. J Clin Endocrinol Metab 87: 2988, 2002.

14. Gomez-Pinillos A and Ferrari AC: mTOR signaling pathway and mTOR inhibitors in cancer therapy. Hematol Oncol Clin North Am 26: 483-505, 2012.

15. Lynch CJ: Role of leucine in the regulation of mTOR by amino acids: revelations from structure-activity studies. J Nutr 131: 861S-865S, 2001.

16. Rosenfeldt MT and Ryan KM: The multiple roles of autophagy in cancer. Carcinogenesis 32: 955-963, 2011.

17. Mah LY and Ryan KM: Autophagy and cancer. Cold Spring Harb Perspect Biol 4: a008821, 2012.

18. Gaytan F, Morales C, Barreiro ML, et al: Expression of growth hormone secretagogue receptor type $1 \mathrm{a}$, the functional ghrelin receptor, in human ovarian surface epithelium, mullerian duct derivatives, and ovarian tumors. J Clin Endocrinol Metab 90: 1798-1804, 2005.

19. Markowska A,Ziółkowska A, Jaszczyńska-Nowinka K, Madry R and Malendowicz LK: Elevated blood plasma concentrations of active ghrelin and obestatin in benign ovarian neoplasms and ovarian cancers. Eur J Gynaecol Oncol 30: 518-522, 2009.

20. Gutierrez JA, Solenberg PJ, Perkins DR, et al: Ghrelin octanoylation mediated by an orphan lipid transferase. Proc Natl Acad Sci USA 105: 6320-6325, 2008.

21. Yang J, Brown MS, Liang G, Grishin NV and Goldstein JL: Identification of the acyltransferase that octanoylates ghrelin, an appetite-stimulating peptide hormone. Cell 132: 387-396, 2008.
22. Lim CT, Kola B, Grossman A and Korbonits M: The expression of ghrelin O-acyltransferase (GOAT) in human tissues. Endocr J 58: 707-710, 2011.

23. Zhang W, Chai B, Li JY, Wang H and Mulholland MW: Effect of des-acyl ghrelin on adiposity and glucose metabolism. Endocrinology 149: 4710-4716, 2008.

24. Hosoda H, Kojima M, Matsuo H and Kangawa K: Ghrelin and des-acyl ghrelin: two major forms of rat ghrelin peptide in gastrointestinal tissue. Biochem Biophys Res Commun 279: 909-913, 2000

25. Inoki K, Corradetti MN and Guan KL: Dysregulation of the TSC-mTOR pathway in human disease. Nat Genet 37: 19-24, 2005.

26. Yang Q and Guan KL: Expanding mTOR signaling. Cell Res 17: 666-681, 2007

27. Laplante M and Sabatini DM: mTOR signaling in growth control and disease. Cell 149: 274-293, 2012.

28. LoRusso PM: Mammalian target of rapamycin as a rational therapeutic target for breast cancer treatment. Oncology 84: 43-56, 2013.

29. Fuchs Y and Steller H: Programmed cell death in animal development and disease. Cell 147: 742-758, 2011.

30. Bergmann A and Steller H: Apoptosis, stem cells, and tissue regeneration. Sci Signal 3: re8, 2010.

31. Meijer AJ: Amino acids as regulators and components of nonproteinogenic pathways. J Nutr 133: 2057S-2062S, 2003.

32. Levine B and Klionsky DJ: Development by self-digestion: molecular mechanisms and biological functions of autophagy. Dev Cell 6: 463-477, 2004

33. Crighton D, Wilkinson S, O'Prey J, et al: DRAM, a p53-induced modulator of autophagy, is critical for apoptosis. Cell 126: 121-134, 2006.

34. Zhang H, Bosch-Marce M, Shimoda LA, et al: Mitochondrial autophagy is an HIF-1-dependent adaptive metabolic response to hypoxia. J Biol Chem 283: 10892-10903, 2008

35. Jung $\mathrm{CH}$, Ro SH, Cao J, Otto NM and Kim DH: mTOR regulation of autophagy. FEBS Lett 584: 1287-1295, 2010.

36. Chang YY, Juhász G, Goraksha-Hicks P, et al: Nutrient-dependent regulation of autophagy through the target of rapamycin pathway. Biochem Soc Trans 37: 232-236, 2009. 